\title{
Studies on the Osmotic Dehydration and Rehydration Characteristics of Pineapple Slices
}

\section{Fasogbon BM*, Gbadamosi SO and Taiwo KA}

Department of Food Science and Technology, Obafemi Awolowo University, Ile-Ife, Nigeria

\begin{abstract}
The study investigated the influence of two osmotic conditions $\left(50^{\circ}\right.$ Brix sugar and $47: 3 \% \mathrm{w} / \mathrm{w}$ sugar/salt solutions) on osmotic dehydration (water loss, solid gain, electrical conductivity and $\mathrm{pH}$ of the medium) and rehydration characteristics (Dry-matter loss, rehydration capacity, electrical conductivity and $\mathrm{pH}$ of the medium) of dried pineapple slices. Pineapple slices were osmotically dehydrated $(4 \mathrm{hr})$, and oven dried $\left(60^{\circ} \mathrm{C}\right.$ for $\left.27 \mathrm{hr}\right)$. Slices were rehydrated at $90^{\circ} \mathrm{C}$ for $15 \mathrm{~min}$ and at room temperature (RT) for $6 \mathrm{hr}$. Osmotic dehydration enhanced solid gain, water loss, dry-matter loss and rehydration capacity. Mass transfer (water loss and solid gain) was higher in sugar/ salt solution than in the sugar solution. Sugar/salt mix reduced the amount of electrolytes released into the medium. Regression models gave a good fit of high $R^{2}$ value when water loss, solid gain, and electrical conductivity variables were related, but dry-matter loss, rehydration capacity, $\mathrm{pH}$ and electrical conductivity gave low $R^{2}$ values.
\end{abstract}

Keywords: Pineapple; Osmotic dehydration; Rehydration; Solid Gain; Water loss; Electrical conductivity; pH; Rehydration capacity; Dry-matter loss

\section{Introduction}

Production of pineapple in Nigeria has expanded over time making her the highest producer in Africa with a total production of 889,000 tonnes in 2009 [1]. The fruit has high sugar content and is rich in vitamins $\mathrm{A}$ and $\mathrm{C}$, over $70 \%$ of the annual production is consumed in the fresh form. The increasing production of the fruit and its high perishable nature with lack of facilities for transportation of the produce from the area of production to the customers provide some necessity to transform it into a more stable form [2].

Dried fruits are rich source of vitamins, minerals, anti-oxidants, and especially fiber due to their concentration during processing. These products are also rich source of energy, particularly if produced by osmo-convective dehydration using concentrated sucrose solutions. Sun drying is the commonest technique employed in the preservation of many agricultural materials in Nigeria but it results in products of low quality. Osmotic dehydration (OD) of fruits as a pretreatment has been reported to reduce energy consumption and improve product quality with a high content of naturally occurring vitamins and microelements [3]. When applied in combination with air drying, OD produces a variety of shelf stable fruit products and lengthens the storage life.

This technology promotes partial removal of water from food by immersion in a concentrated hypertonic solution leaving a material that will need shorter drying times than the original food material, making this process more economical. Furthermore, increased sugar content in the final product improves the organoleptic qualities of the end product because some of the acids are removed from the fruit during osmotic dehydration, so a sweeter product than ordinary dried fruit is obtained [4]. Mass transfer rate during osmotic dehydration is affected by factors such as temperature, concentration of the osmotic medium, size and geometry of the sample, sample to solution ratio and the degree of agitation. Pretreatment has also been reported to enhance the mass transfer kinetics during osmotic dehydration [5].

Rehydration is a complex process aimed at the restoration of raw material properties when dried material is in contact with water. During rehydration, absorption of water into the tissue and leaching out of product solutes (sugar, acids, minerals, vitamins etc.) into the medium both occur concurrently [6]. Dry material, subjected to rehydration, undergoes many chemical and physical changes owing to the property of water imbibition and solute loss. Imbibition of water by dry material is dependent on the porosity of the material which is related to drying and the predrying processes involved. Other factors of interest during rehydration include: temperature, the chemical composition of the product, drying techniques and conditions, composition of the rehydrating medium, etc. [7].

Electrical conductivity of a solution is the measurement of all ions present. A high concentration of ions will correspond to high conductivity (assuming there is no reaction between the ions present). The electrical conductivity of foods increases with temperature, applied voltage, concentration of the electrolytes, food particle size and type of pretreatment. Changes in electrical conductivity values may be due to high temperature heating causing dissolution of cell wall components and increase in ionic mobility [8].

The aim of this study is to investigate the influence of different osmotic conditions on the characteristics of osmotically dehydrated pineapple slices and their rehydration characteristics at different temperatures.

\section{Materials and Methods}

\section{Sample preparation}

Smooth cayenne variety of pineapples (Ananas comosus) was procured from a local market in Ile-Ife, Nigeria. The fresh pineapple

*Corresponding author: B. M Fasogbon, Department of Food Science and Technology, Obafemi Awolowo University, Ile-Ife, Nigeria, E-mail: tjwonderus@yahoo.com

Received February 15, 2013; Accepted March 18, 2013; Published March 24 2013

Citation: Fasogbon BM, Gbadamosi SO, Taiwo KA (2013) Studies on the Osmotic Dehydration and Rehydration Characteristics of Pineapple Slices. J Food Process Technol 4: 220. doi:10.4172/2157-7110.1000220

Copyright: @ 2013 Fasogbon BM, et al. This is an open-access article distributed under the terms of the Creative Commons Attribution License, which permits unrestricted use, distribution, and reproduction in any medium, provided the original author and source are credited. 
fruits were purchased in batches to avoid variation in samples, the fruits were washed, manually peeled and cut to a uniform diameter (40 $\pm 0.1 \mathrm{~mm})$ and thickness $(5 \pm 0.2 \mathrm{~mm})$ using a sharp metal borer and a knife. The samples were gently blotted with tissue paper to remove adhering surface water and weighed.

An aqueous sugar solution $\left(50^{\circ} \mathrm{Brix}\right.$ of raffinade grade) and sugar/ salt solution $(47: 3 \% \mathrm{w} / \mathrm{w})$ were used as the osmotic dehydration media. The sugar solution was prepared by dissolving $50 \mathrm{~g}$ of sugar in water and made up to $100 \mathrm{ml}$ at $40^{\circ} \mathrm{C}$ to ensure complete dissolution [9]. The sugar/salt solution was composed of $47 \mathrm{~g}$ of sucrose, $3 \mathrm{~g}$ of $\mathrm{NaCl}$ and made up to $100 \mathrm{ml}$ of water [10].

\section{Osmotic dehydration}

The pineapple slices were immersed in a beaker containing the osmotic solution and maintained at $40^{\circ} \mathrm{C}$ in a thermostatically controlled static water bath (Julabo, SW22, Germany). The ratio of fruit pieces to that of the medium was maintained at 1:10 to ensure that the concentration of the osmotic solution did not change significantly during the experiment [11]. Samples were withdrawn at $60,120,180$ and $240 \mathrm{~min}$ with their surfaces being gently blotted with tissue paper before weighing.

\section{Air drying of the samples}

The osmotically dehydrated pineapple slices were arranged in a tray and placed in the hot air oven (MRC Oven/Incubator, Model DP/DK $500 / 600 / 800$, made by MRC Ltd. Hahystadnit) at $60^{\circ} \mathrm{C}$ for $27 \mathrm{hr}$ to obtain dried products. The dried samples were stored in an airtight polythene bag for further use. Analysis carried out during the osmotic dehydration process includes water loss, solid gain, electrical conductivity and $\mathrm{pH}$ of the medium. Computation of water loss and solid gain during osmotic dehydration was based on the assumption that there was no change in the total insoluble solid content of the sample during immersion [9].

$$
\begin{aligned}
& \text { Solid gain }(g / g)=\left(M_{f}-S_{o}\right) / S_{o} \\
& \text { Water loss }_{(\text {wet-basis })}=\left[\left(M_{o}-S_{o}\right)-\left(M_{o d}-M_{f}\right)\right] / M_{o}-S_{o}
\end{aligned}
$$

Where $\mathrm{M}_{\mathrm{o}}=$ Initial sample weight before osmotic dehydration $(\mathrm{g})$; $\mathrm{M}_{\mathrm{od}}=$ Sample weight after osmotic dehydration at time $\mathrm{t}(\mathrm{g}) ; \mathrm{M}_{\mathrm{f}}=$ Final weight of dried sample (g); $S_{o}=$ Initial solid content (g).

\section{Rehydration}

The osmotically dehydrated samples were rehydrated at two different conditions. The first set was placed in a glass beaker containing distilled water at RT for $6 \mathrm{hr}$. The other set was placed in distilled water at $90^{\circ} \mathrm{C}$ for $15 \mathrm{~min}$ [12]. The samples were removed from the beaker at stipulated intervals; adhering water was carefully blotted out using paper towel and weighed accordingly. After rehydration, the samples were dried in the air oven at $60^{\circ} \mathrm{C}$ for $27 \mathrm{hr}$ to determine the solid content.

During the rehydration process, water uptake, solid loss, electrical conductivity and the $\mathrm{pH}$ of the medium were determined. The following expressions described by Taiwo et al. [13] were used in the computations:

$$
\begin{aligned}
& \text { Re hydration Capacity at time } t(\%)=\left(M_{r} / M_{t}\right) \times 100 \\
& \text { Dry Matter Loss }(\%)=\left[\left(M_{g} / S_{r}\right) / M_{g}\right] \times 100
\end{aligned}
$$

Where $M_{r}=$ Rehydrated weight at time $t(g) ; M_{t}=$ Sample weight after pretreatment prior to $\mathrm{OD}(\mathrm{g})$; $\mathrm{Mg}=$ weight of air dried sample before rehydration $(\mathrm{g}) ; \mathrm{S}_{\mathrm{r}}=$ is the weight of dried sample after rehydration $(\mathrm{g})$.

\section{Electrical conductivity and $\mathrm{pH}$ measurement}

Electrical conductivity of the osmotic solutions was measured using conductivity meter (Hanna Instruments: H1721313, Italy). The probe was dipped in the solution at $25^{\circ} \mathrm{C}$ and the displayed value read on the conductivity meter. $\mathrm{pH}$ probe (Hanna Instruments, 800-276868, Italy) was dipped in the solutions to measure the $\mathrm{pH}$ of the various media.

\section{Statistical analysis}

Statistical analysis was carried out using Microsoft Excel and SPSS 15.0 for ANOVA and $t$ test as appropriate.

\section{Results and Discussion}

\section{Mass transfer during the osmotic dehydration of pineapple}

The data on solid gain (\%) and water loss (\%) by pineapple slices immersed in sugar and sugar/salt solutions are presented in figure 1a and $1 \mathrm{~b}$ respectively. The amount of solid uptake in sugar/salt solution was between $44.52 \%$ and $59.12 \%$ while that of sugar solution was between $49.30 \%$ and $52.17 \%$.

Solid uptake in sugar solution had no significant $(P>0.05)$ change over time, but the most significant changes in sugar/salt solution took place in the first $3 \mathrm{hr}$ of the osmotic dehydration process (Figure 1a). This suggests that it is not necessary to dehydrate the pineapple slices in sugar/salt solution for periods longer than $3 \mathrm{hr}$ if the objective is to impregnate the sample with solids. Taiwo et al. [10] worked on strawberry halves and also reported optimal solid gain at $3 \mathrm{hr}$.

The sugar/salt solution used in the study enhanced solid gain more than sugar solution alone. This result agrees with the trend of solid gained by strawberries in glucose, sucrose and $\mathrm{NaCl}$-sucrose solutions as reported by Taiwo et al. [10]. Lerici et al. [14] reported that the addition of $\mathrm{NaCl}$ (up to 2\%) did not give indicative changes in the solid gain of apples. In this study, $3 \%$ salt was used and this may account for the increase in solid gained over sugar solution. The amount of water loss increased with increase in immersion time up to $4 \mathrm{hr}$. Pineapple slices immersed in sugar/salt solution exhibited a significantly greater $(P<0.05)$ water loss $(21.28$ to $31.86 \%)$ up to the fourth hour of osmotic dehydration when compared to those samples immersed in sugar solution (15.23 to $24.36 \%)$. Other authors have reported high water loss from fruits in sugar/salt solutions $[10,15]$. The high capacity of $\mathrm{NaCl}$ to lower water activity has been reported to increase the driving force of the drying process. Addition of $\mathrm{NaCl}$ at low concentration has been reported to attenuate the sweetness of the fruit [10].

Equations were fitted to the data to establish mathematical relations between water loss and solid gain. High correlation values were obtained $(0.945 \leq \mathrm{r} \leq 0.999)$ for both osmotic solutions (Table 1a and 1b). $R^{2}$ values for the quadratic and cubic equations were very close. Suresh and Devi [16] reported similar $R^{2}$ values for models generated to fit the different processing variables in optimization of mass transfer process of OD pineapple slices.

\section{Electrical conductivity (EC) and $\mathrm{pH}$ of the osmotic dehydration media}

Electrical conductivity values (Figure 2a) of the osmotic sugar medium increased with OD time with sugar solution $(23.30$ to $69.30 \mu \mathrm{s} /$ $\mathrm{cm}$ ) exhibiting higher EC values than the sugar/salt solution (14.82 to $15.19 \mu \mathrm{s} / \mathrm{cm})$. Less than $5 \%$ change in the EC values of the sugar $/ \mathrm{salt}$ medium over the $4 \mathrm{hr}$ period was recorded. The EC values of the sugar/ 
salt solution are lower than the range of values reported by Taiwo et al. [10] for strawberry halves.

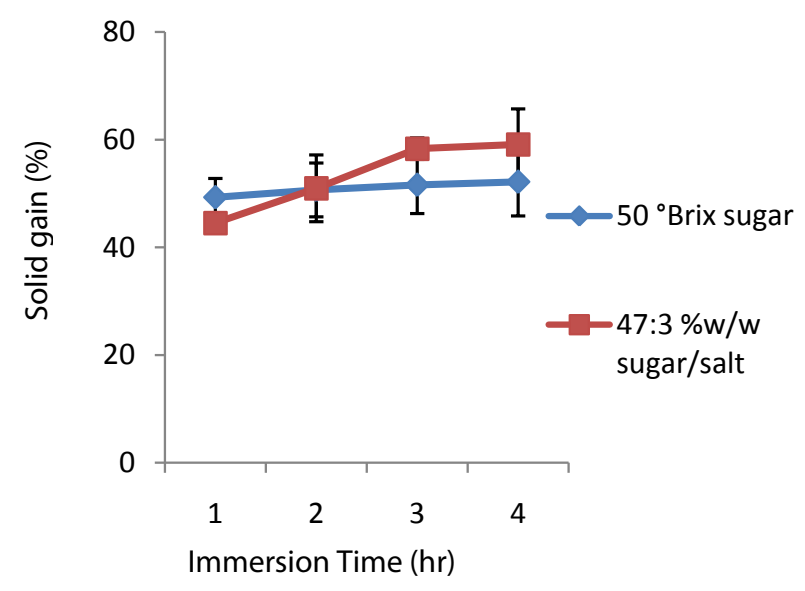

Figure 1a: Solid gain during osmotic dehydration of pineapple slices in sugar, and sugar/salt solutions.

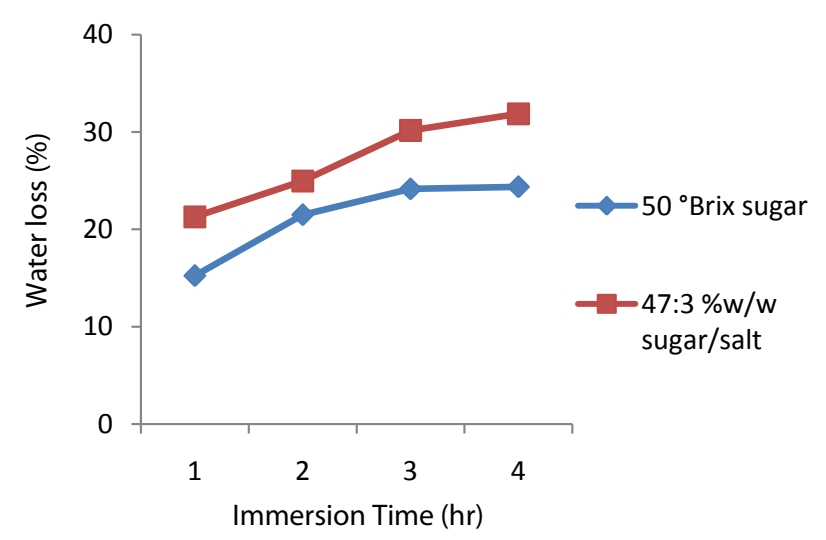

Figure 1b: Water loss during osmotic dehydration of pineapple slices in sugar, and sugar/salt solutions.

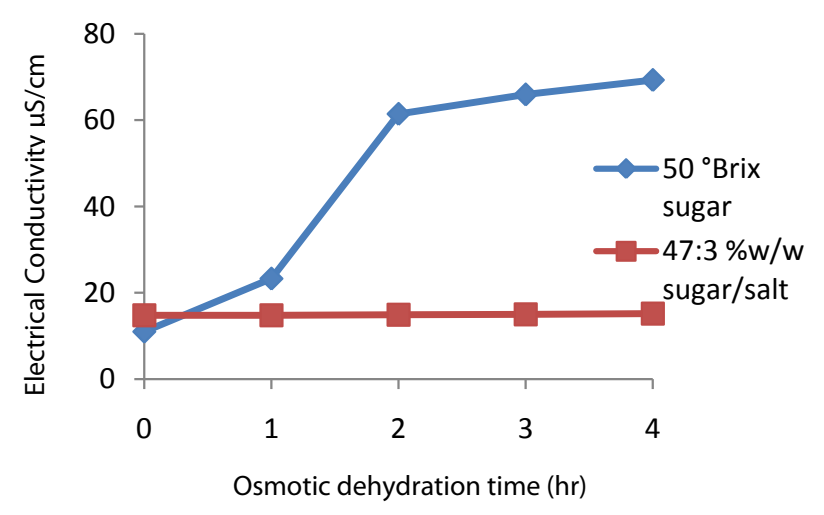

Figure 2a: Effect of OD time on electrical conductivity of different immersion solution of osmotic dehydrated pineapple.
A mathematical relationship between water loss and electrical conductivity showed a good relationship which is expected since the electrolytes are released through the fluids. Quadratic equation gave the best correlation for samples dehydrated in sugar solution with $R^{2}$ of 0.996 , while cubic equations gave $R^{2}$ value of 0.914 for samples dehydrated in sugar/salt solution.

Changes in $\mathrm{pH}$ of the osmotic solution with time were presented in figure 2 b. For sugar solution, $\mathrm{pH}$ showed a slight decrease from 5.4 to 5.1 while in sugar/salt solution it decreased from 5.1 to 4.9 . The $\mathrm{pH}$ fluctuated with osmotic dehydration time but the changes were not significant, and these values have advantage of inhibiting microbial growth [17]. Equations were fitted to establish correlation relationships between $\mathrm{pH}$ and electrical conductivity of the medium but the degree of fit were low $(0.042<\mathrm{r}<0.539)$.

\section{Rehydration capacity and dry-matter loss of dried pineapple slices}

Rehydration capacity (RC) of dried non-osmotically dehydrated slices and pineapple slices osmotically dehydrated in sugar and sugar/ salt solution were reported in figure 3a-3d, similar trends were observed for samples rehydrated at RT and $90^{\circ} \mathrm{C}$. The RC values of samples osmotically dehydrated in sugar/salt solution (52.32\%-70.07\%) were higher than the values of samples osmotically dehydrated in sugar solution $(40.50 \%-54.40 \%)$ at $90^{\circ} \mathrm{C}$.

Osmotic dehydration time influenced the RC of the samples osmotically dehydrated in sugar solution (Figure 4a). RC increased with longer osmotic dehydration time. Dried non-osmotically dehydrated pineapple slices had the least RC values (37-38\%) and are significantly different $(P<0.05)$ from those subjected to osmotic dehydration. This suggests that RC is improved when pineapples are osmotically dehydrated prior to drying, compared to the dried samples not osmotically dehydrated.

$\mathrm{RC}$ was influenced by rehydrating temperature, at $90^{\circ} \mathrm{C}$, rehydration time was not significant on RC between 5 and $15 \mathrm{~min}$. However at RT, $\mathrm{RC}$ increased with rehydration time up to $2 \mathrm{hr}$ after which only slight increases were recorded (up to $6 \mathrm{hr}$ ) for samples osmotically dehydrated in both solutions. This result suggests an optimal rehydration time of 2 $\mathrm{hr}$ at RT. With prolonged rehydration duration, the moisture content increased to a maximum value and remained almost constant with increase in soaking time [18]. Rastogi et al. [5] reported that structural changes due to pretreatment resulted in compactness of the cellular structure, and this may be responsible for the slow water uptake during rehydration. However this is not in agreement with the observation of Adeomowaye et al. [9] that solid uptake during OD minimized shrinkage thus reducing the compactness of the dried samples, which resulted in high RC values especially in the sugar/salt mix. The result of rehydration capacity in this study agrees with literature values $[19,20]$.

Both osmotic medium did not affect the RC when rehydrated at $\mathrm{RT}$, with maximum RC ranging between $67-69 \%$. There was a significant difference $(P<0.05)$ in the $\mathrm{RC}$ of samples rehydrated at $90^{\circ} \mathrm{C}$. Samples osmotically dehydrated in salt/sugar solution had up to $70 \% \mathrm{RC}$ while those in sugar solution had a maximum of $54 \%$. This result suggests that samples dehydrated in salt/sugar solution were not affected by the rehydration temperature. Taiwo et al. [19] also reported lower RC for apple samples rehydrated at $90^{\circ} \mathrm{C}$ compared to samples at RT. Rehydration at lower temperatures seems to promote faster water diffusion into the product through swelling and plasticizing of membranes [20]. 
Citation: Fasogbon BM, Gbadamosi SO, Taiwo KA (2013) Studies on the Osmotic Dehydration and Rehydration Characteristics of Pineapple Slices. J Food Process Technol 4: 220. doi:10.4172/2157-7110.1000220

Page 4 of 8

\begin{tabular}{|c|c|c|c|c|}
\hline \multirow[b]{2}{*}{ Variables } & \multicolumn{4}{|c|}{$\mathbf{R}^{2}$} \\
\hline & OD medium & Linear & Quadratic & Cubic \\
\hline$W L$ and SG & Sugar & 0.945 & 0.945 & 0.999 \\
\hline WL and SG & Sugar/Salt & 0.985 & 0.993 & 0.993 \\
\hline $\mathrm{pH}$ and $\mathrm{EC}$ & Sugar & 0.160 & 0.516 & 0.539 \\
\hline $\mathrm{pH}$ and $\mathrm{EC}$ & Sugar/Salt & 0.042 & 0.042 & 0.042 \\
\hline $\mathrm{EC}$ and $\mathrm{WL}$ & Sugar & 0.968 & 0.996 & 0.996 \\
\hline$E C$ and $W L$ & Sugar/Salt & 0.884 & 0.909 & 0.914 \\
\hline $\mathrm{DM}_{\mathrm{L}}$ and $\mathrm{RC}\left(90^{\circ} \mathrm{C}\right)$ & Sugar & 0.525 & 0.628 & 0.629 \\
\hline $\mathrm{DM}_{\mathrm{L}}$ and $\mathrm{RC}\left(90^{\circ} \mathrm{C}\right)$ & Sugar/Salt & 0.777 & 0.825 & 0.825 \\
\hline $\mathrm{DM}_{\mathrm{L}}$ and $\mathrm{RC}(\mathrm{RT})$ & Sugar & 0.443 & 0.513 & 0.511 \\
\hline $\mathrm{DM}_{\mathrm{L}}$ and $\mathrm{RC}(\mathrm{RT})$ & Sugar/Salt & 0.021 & 0.045 & 0.048 \\
\hline $\mathrm{EC}$ and $\mathrm{RC}\left(90^{\circ} \mathrm{C}\right)$ & Sugar & 0.237 & 0.364 & 0.364 \\
\hline $\mathrm{EC}$ and $\mathrm{RC}\left(90^{\circ} \mathrm{C}\right)$ & Sugar/Salt & 0.137 & 0.248 & 0.248 \\
\hline $\mathrm{EC}$ and $\mathrm{RC}(\mathrm{RT})$ & Sugar & 0.043 & 0.206 & 0.205 \\
\hline $\mathrm{EC}$ and $\mathrm{RC}(\mathrm{RT})$ & Sugar/Salt & 0.488 & 0.497 & 0.498 \\
\hline
\end{tabular}

Table 1a: Model Equation from Regression Analysis.

\begin{tabular}{|c|c|c|c|c|}
\hline \multirow[b]{2}{*}{ Variables } & \multicolumn{4}{|c|}{$\mathbf{R}^{2}$} \\
\hline & OD medium & Linear & Quadratic & Cubic \\
\hline WL and SG & Sugar & $-146.644+3.297 x$ & $-146.644+3.297 x+x^{2}$ & $-146.644+3.297 x+x^{2}+0 x^{3}$ \\
\hline WL and SG & Sugar/Salt & $36.755-1.129 x$ & $36.755-1.129 x+0.018 x^{2}$ & $36.755-1.129 x+0.018 x^{2+} 0 x^{3}$ \\
\hline $\mathrm{pH}$ and $\mathrm{EC}$ & Sugar & $5.148+0 x$ & $5.148+0.000692 x^{2}$ & $5.148+0.000692 x^{2}-1.0015 E-005 x^{3}$ \\
\hline $\mathrm{pH}$ and $\mathrm{EC}$ & Sugar/Salt & $-205.5+27.90 x$ & $-205.5+27.90 x-0.925 x^{2}$ & $-205.5+27.90 x-0.925 x^{2}+0 x^{3}$ \\
\hline $\mathrm{EC}$ and $\mathrm{WL}$ & Sugar & $-204.695+21.283 x$ & $-204.695+21.283 x-0.414 x^{2}$ & $-204.695+21.283 x-0.414 x^{2+} 0 x^{3}$ \\
\hline$E C$ and $W L$ & Sugar/Salt & $14.955+0 \mathrm{x}$ & $14.955+0 x-0.0011 x^{2}$ & $14.955+0 x-0.0011 x^{2}+4.338 E-005 x^{3}$ \\
\hline $\mathrm{DM}_{\mathrm{L}}$ and $\mathrm{RC}\left(90^{\circ} \mathrm{C}\right)$ & Sugar & $130.081-4.900 x$ & $130.081-4.900 x+0.0575 x^{2}$ & $130.081-4.900 x+0.0575 x^{2+} 0 x^{3}$ \\
\hline $\mathrm{DM}_{\mathrm{L}}$ and $\mathrm{RC}\left(90^{\circ} \mathrm{C}\right)$ & Sugar/Salt & $347.0-13.85 x$ & $347.0-13.85 \times 0.161 x^{2}$ & $347.0-13.85 \times 0.161 x^{2}+0 x^{3}$ \\
\hline $\mathrm{DM}_{\mathrm{L}}$ and $\mathrm{RC}(\mathrm{RT})$ & Sugar & $-197.618+10.135 x$ & $-197.618+10.135 x-0.101 x^{2}$ & $-197.618+10.135 x-0.101 x^{2+} 0 x^{3}$ \\
\hline $\mathrm{DM}_{\mathrm{L}}$ and $\mathrm{RC}(\mathrm{RT})$ & Sugar/Salt & $71.73-0.532 x$ & $71.73-0.532 \times 0.007 x^{2}$ & $71.73-0.532 \times 0.007 x^{2}+0 x^{3}$ \\
\hline $\mathrm{EC}$ and $\mathrm{RC}\left(90^{\circ} \mathrm{C}\right)$ & Sugar & $-1287.140+57.578 x$ & $-1287.140+57.578 x-0.571 x^{2}$ & $-1287.140+57.578 x-0.571 x^{2+} 0 x^{3}$ \\
\hline $\mathrm{EC}$ and $\mathrm{RC}\left(90^{\circ} \mathrm{C}\right)$ & Sugar/Salt & $-753.226+27.208 x$ & $-753.226+27.208 x-0.21559 x^{2}$ & $-753.226+27.208 x-0.21559 x^{2+} 0 x^{3}$ \\
\hline $\mathrm{EC}$ and $\mathrm{RC}(\mathrm{RT})$ & Sugar & $-999.005+38.848 x$ & $-999.005+38.848 x-0.345 x^{2}$ & $-999.005+38.848 x-0.345 x^{2+} 0 x^{3}$ \\
\hline $\mathrm{EC}$ and $\mathrm{RC}(\mathrm{RT})$ & Sugar/Salt & $-401.247+8.379 x$ & $-401.247+8.379 x+0 x^{2}$ & $8.379 x-401.247+0 x^{3}$ \\
\hline
\end{tabular}

$\mathrm{WL}-$ Water loss

SG - Solid gain

EC - Electrical conductivity

$\mathrm{DML}$ - Dry matter loss

$\mathrm{RC}$ - Rehydration capacity

Table 1b: $R^{2}$ Value from Regression Analysis.

Maximum dry-matter loss (DML) from samples dehydrated in sugar solution and rehydrated at $90^{\circ} \mathrm{C}$ ranged between $23 \%$ and $34 \%$. Percentage DML for samples dehydrated in sugar/salt solution ranged between $40 \%$ and $54 \%$ (Figure 3e) which was higher than the values obtained for dried non-osmotically dehydrated pineapple and samples dehydrated in sugar solution. Femenia et al. [21] suggested that modification of the structural arrangement of pectins (due to thermal degradation) may influence solubility of pectic polymers.

At RT the amount of DML increased with rehydration time. Dried non-osmotically dehydrated pineapple slices had a DML ranging between $37.05 \%$ and $47.25 \%$, while pineapple samples dehydrated in sugar solution exhibited a DML ranging between $25.35 \%$ and $58.57 \%$, whereas samples dehydrated in sugar/salt solution had a DML which ranged between $10.86 \%$ and $59.92 \%$. For samples dehydrated in sugar solution, DML appeared to stabilize with very slight increase after 3 hr (Figure 3f). DML from samples dehydrated in sugar/salt solution increased till the end of the rehydration process but the rate of loss decreased with increase in time. Over $90 \%$ of the DML had taken place in the first three hours of rehydration. Influence of rehydration time on samples osmotically dehydrated in sugar/salt solution is mainly at the first $3 \mathrm{hr}$ of rehydration process, after which increasing rehydration time did not yield higher dry-matter loss.

Highest DML was obtained at RT, this agrees with the report of Taiwo et al. [19] on rehydration of apples. The immersion time at $90^{\circ} \mathrm{C}$ is shorter (5-15 $\mathrm{min}$ ) compared to the immersion time of $6 \mathrm{hr}$ at RT, more solids (both absorbed sugar and part of the fruit dry matter) are expected to leach as immersion time is extended hence the trend observed.

Regression analysis was carried out to develop mathematical models for dry-matter loss and rehydration capacity of pineapple slices. Samples dehydrated in sugar solution and rehydrated at $90^{\circ} \mathrm{C}$ showed that quadratic equations gave a better fit with $R^{2}$ value of 0.628 . Quadratic equations gave $R^{2}$ value of 0.825 for samples dehydrated in sugar/salt solution and rehydrated at $90^{\circ} \mathrm{C}$, but second order equations gave a better fit with $R^{2}$ value of 0.989 . The mathematical relationships were influenced by rehydrating temperature as samples rehydrated at RT had low $R^{2}$ values $(0.021<\mathrm{r}<0.513)$. At both temperatures, the degree of fit was better with sugar solutions than in sugar/salt solution. 
Citation: Fasogbon BM, Gbadamosi SO, Taiwo KA (2013) Studies on the Osmotic Dehydration and Rehydration Characteristics of Pineapple Slices. J Food Process Technol 4: 220. doi:10.4172/2157-7110.1000220

Page 5 of 8

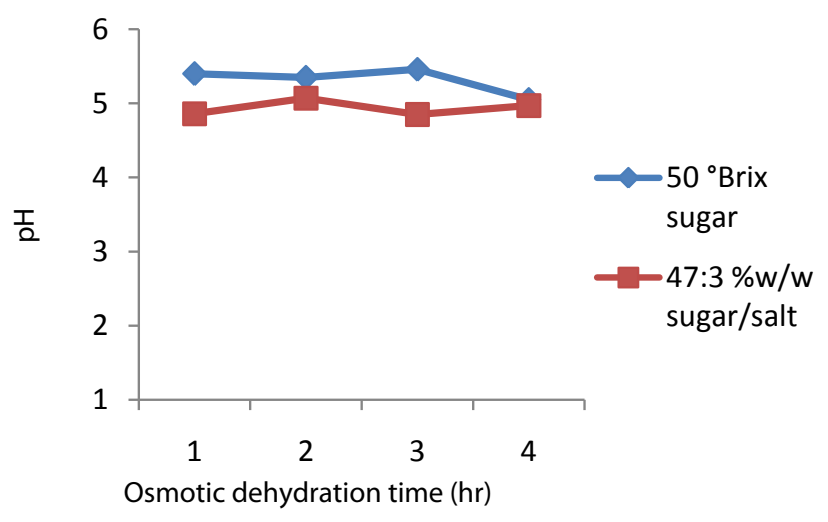

Figure 2b: Effect of OD time on $\mathrm{pH}$ of different immersion solution of osmotic dehydrated pineapple.

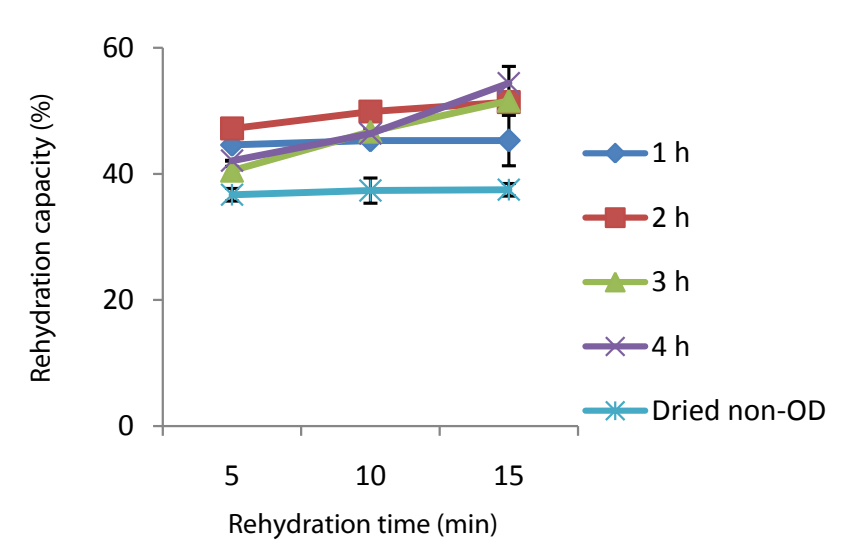

Figure 3a: Effects of rehydration time at $90^{\circ} \mathrm{C}$ and $\mathrm{OD}$ time on $\mathrm{RC}$ of pineapple slices dehydrated in sugar solution.

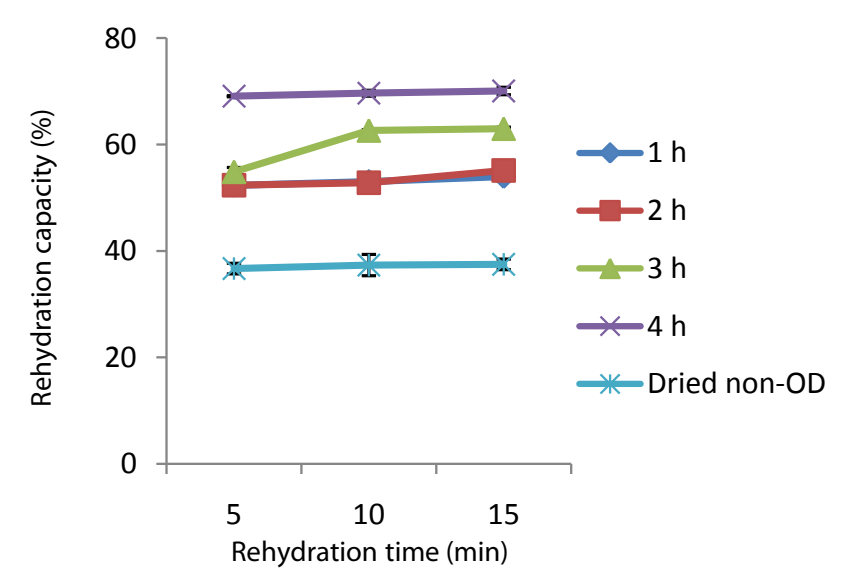

Figure 3b: Effects of rehydration time at $90^{\circ} \mathrm{C}$ and $\mathrm{OD}$ time on $\mathrm{RC}$ of pineapple slices dehydrated in sugar/salt solution.

\section{Electrical conductivity of the rehydration media}

The influence of osmotic conditions and rehydration time on the electrical conductivity of the immersion medium of rehydrated pineapple slices at $90^{\circ} \mathrm{C}$ showed that $\mathrm{EC}$ values increased with rehydration time for all conditions, the values were higher in sugar medium than sugar/salt medium (Figure 4a). The EC values reduced as osmotic dehydration time increased (i.e. $1 \mathrm{hr}>2 \mathrm{hr}>3 \mathrm{hr}>4 \mathrm{hr}$ ) for samples dehydrated in sugar solution at both temperature studied. In sugar/salt solution, the osmotic dehydration time had no influence on the EC of the rehydrating medium.

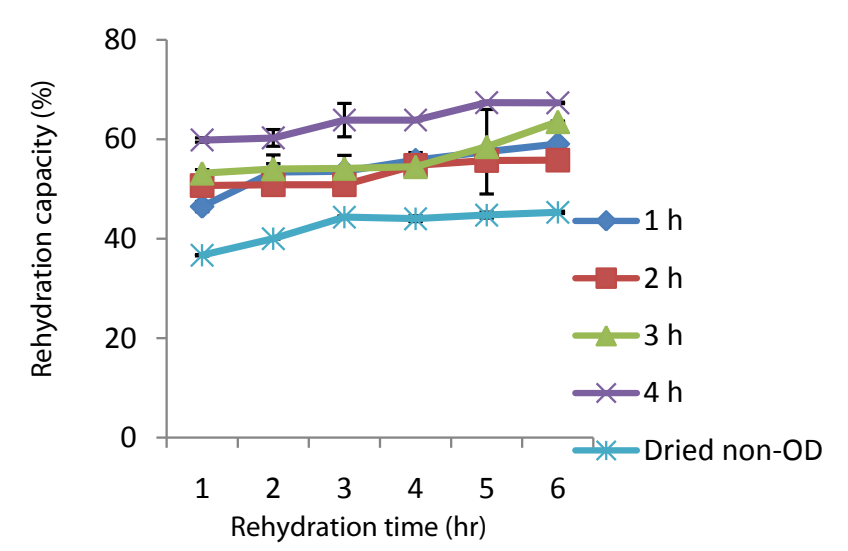

Figure 3c: Effects of rehydration time at $24^{\circ} \mathrm{C}$ and $\mathrm{OD}$ time on $\mathrm{RC}$ of pineapple slices dehydrated in sugar solution.

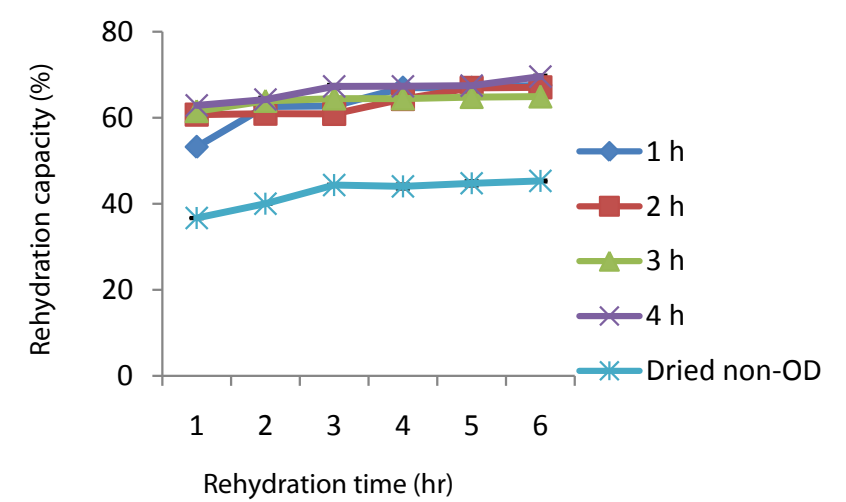

Figure 3d: Effects of rehydration time at $24^{\circ} \mathrm{C}$ and $\mathrm{OD}$ time on $\mathrm{RC}$ of pineapple slices dehydrated in sugar/salt solution.

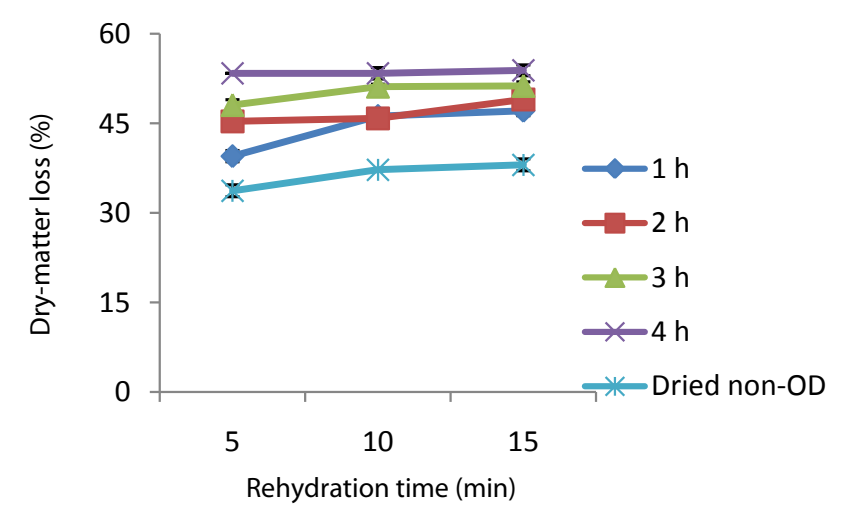

Figure 3e: Effects of rehydration time at $90^{\circ} \mathrm{C}$ and $\mathrm{OD}$ time on DML from pineapple slices dehydrated in sugar/salt solution. 


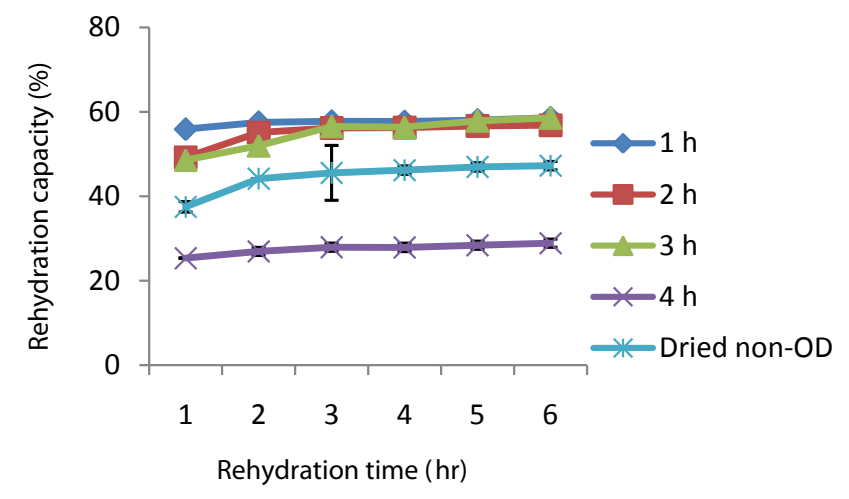

Figure 3f: Effects of rehydration time at room temperature and OD time on $\mathrm{DML}$ from pineapple slices dehydrated in sugar solution.

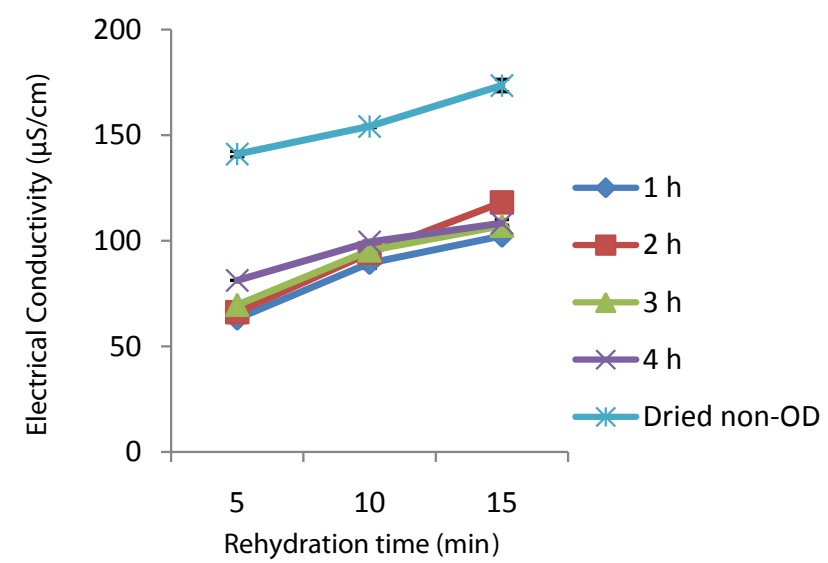

Figure 4a: Effects of rehydration time on the EC of immersion solution of pineapple rehydrated at $90^{\circ} \mathrm{C}$ in sugar/salt solution.

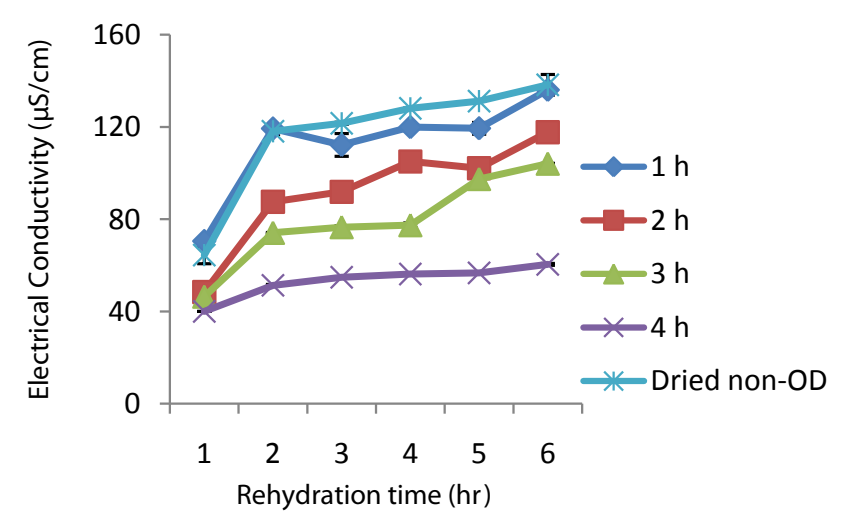

Figure 4b: Effects of rehydration time on the EC of immersion solution of pineapple rehydrated at room temp in sugar solution.

Electrical conductivity values of rehydration medium of samples dehydrated in sugar solution for 1-2 hr is greater than that of 3-4 hrs at RT (Figure $4 \mathrm{~b}$ ). It is probable that the electrolytes and ions not fully leached out during osmotic dehydration (1-2hr) were leached

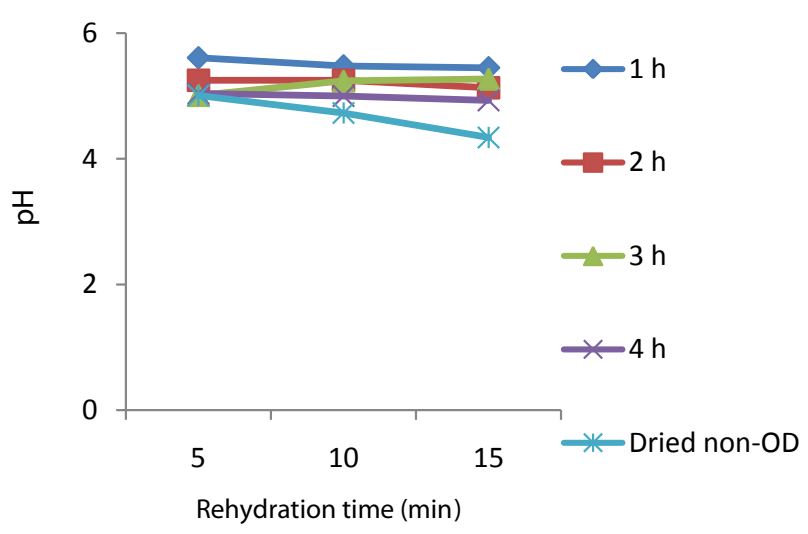

Figure 4c: Effects of rehydration time on the $\mathrm{pH}$ of the immersion solution of pineapples rehydrated at $90^{\circ} \mathrm{C}$ in sugar solution.

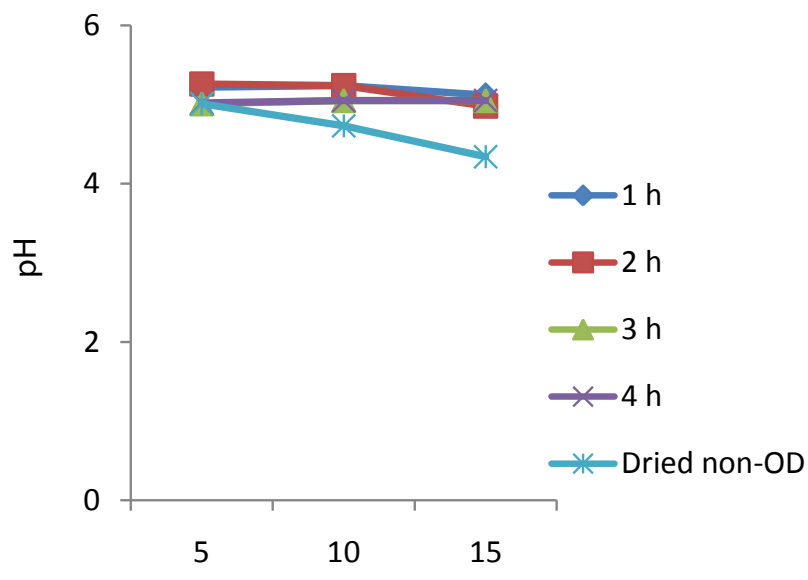

Rehydration time (hr)

Figure 4d: Effects of rehydration time on the $\mathrm{pH}$ of the immersion solution of pineapples rehydrated at $90^{\circ} \mathrm{C}$ in sugar/salt solution.

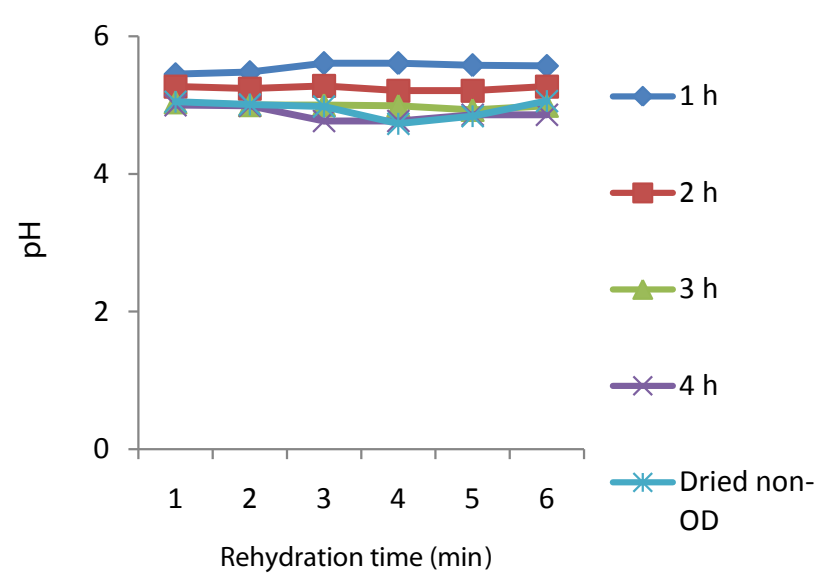

Figure 4e: Effects of rehydration time on the $\mathrm{pH}$ of the immersion solution of pineapples rehydrated at room temperature in sugar solution. 
Citation: Fasogbon BM, Gbadamosi SO, Taiwo KA (2013) Studies on the Osmotic Dehydration and Rehydration Characteristics of Pineapple Slices. J Food Process Technol 4: 220. doi:10.4172/2157-7110.1000220

out during the rehydration process [22]. Higher values were obtained for samples osmotically dehydrated in sugar solution which ranged from 105.85-198.85 $\mu \mathrm{s} / \mathrm{cm}$ than samples dehydrated in sugar/salt solution $(63.05$ and $118.11 \mu \mathrm{s} / \mathrm{cm})$. This is note worthy because samples dehydrated in salt/sugar solution had higher solid gain. This result suggests that the salt ions have a greater binding effect on electrolyte release than the sugar solution.

Singh et al. [18] reported that an increase in electrolyte leakage could occur if the activity or the efficiency of the transport system had been altered. Electrical conductivity is a measure of soluble solids or electrolytes in the medium, which is indicative of leakage of intercellular ions from sample tissue.

Results on effects of temperature on the electrical conductivity of the rehydration medium showed that at $90^{\circ} \mathrm{C}$ higher values were obtained for samples osmotically dehydrated in sugar solution but lower values were obtained at RT. This result agrees with the electrical conductivity trend reported by Taiwo et al. [19] at the same temperature. The rate and extent of electrolyte released was influenced by pre-drying treatments and rehydration temperature [19].

Low $R^{2}$ values were obtained when establishing correlation between rehydration capacity and electrical conductivity $(0.043<\mathrm{r}<0.498)$.

\section{$\mathrm{pH}$ of the rehydration media}

The $\mathrm{pH}$ values of the immersion solution decreased as rehydration time increased but decreased with increase in OD time although the impact of OD time was not significant (Figure $4 \mathrm{c}-4 \mathrm{f}$ ). At $90^{\circ} \mathrm{C}$ the $\mathrm{pH}$ of the medium of dried non-OD reduced from 5.01-4.34, rehydration time was significant $(P<0.05)$ but decreased after $10 \mathrm{~min}$ of rehydration. The $\mathrm{pH}$ of the medium of samples dehydrated in sugar solution reduced from 5.61 to 4.95 , while that of samples dehydrated in sugar/salt solution reduced from 5.26 to 4.34 (Figure $4 \mathrm{c}$ and $4 \mathrm{~d}$ ). Figures $4 \mathrm{e}$ and $4 \mathrm{f}$ depict the $\mathrm{pH}$ of rehydration medium at RT. The rate and extent of decrease in $\mathrm{pH}$ is slower at this temperature compared to those rehydrated at $90^{\circ} \mathrm{C}$. The $\mathrm{pH}$ value of dried non-OD rehydration medium reduced from 5.06 to 4.73 and was not significantly different $(P>0.05)$ from the osmotically dehydrated samples.

The $\mathrm{pH}$ value of the rehydration medium for samples osmotically dehydrated in sugar solution reduced from 5.58 to 4.77 while the value

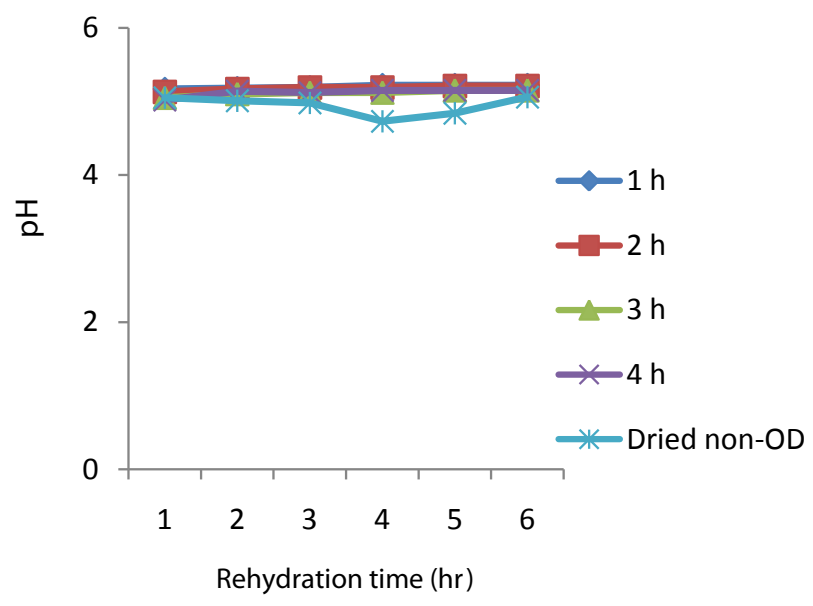

Figure 4f: Effects of rehydration time on the $\mathrm{pH}$ of the immersion solution of pineapples rehydrated at room temperature in sugar/salt solution. obtained from rehydration medium of samples dehydrated in sugar/ salt solution reduced from 5.22 to 5.02. OD time was not significant. $\mathrm{pH}$ values of the rehydration medium of dried non-osmotically dehydrated samples were lower than the osmotically dehydrated samples and this indicates that solids picked up during osmotic dehydration contributed to increased $\mathrm{pH}$.

The results of the study showed that there is great potential in the use of osmotic dehydration in the preservation of pineapple fruit. Osmotic solutions used in this study enhanced solid gain. Solid gain is optimal by $3 \mathrm{hr}$ of soaking and water loss increased up to $4 \mathrm{hr}$. With increase in osmotic dehydration time, leaching of electrolytes (EC) increased while the $\mathrm{pH}$ decreased. The $\mathrm{pH}$ values did not change significantly during osmotic dehydration process.

Impact of osmotic dehydration time on RC was not significant beyond 2 hrs of rehydration for both media used. Osmotically dehydrated samples had higher rehydration capacity than dried nonosmotically dehydrated samples. Dry-matter loss increased with time and it is influenced by osmotic dehydration and rehydration time. Electrical conductivity increased in value with increase in rehydration time. Osmotic dehydration prior to drying reduced the amount of electrolytes released during rehydration. The $\mathrm{pH}$ of the rehydration media decreased with increase in rehydration and osmotic dehydration time.

\section{References}

1. FAO (2011) FAO Agricultural Production Statistic Database (FAOSTAT). Food and Agricultural Organization of the United Nations.

2. Koubala BB, Kansci G, Mbome LI, Crepeau MJ, Thibault JF, et al. (2008) Effect of extraction conditions on some physicochemical characteristics of pectins from "Amelioree" and "Mango" mango peels. Food Hydrocolloid 22: 1345-1351.

3. Moreira R, Sereno AM (2003) Evaluation of mass transfer coefficients and volumetric shrinkage during osmotic dehydration of apple using sucrose solutions in static and non-static conditions. J Food Eng 57: 25-31.

4. Falade KO, Aworh OC (2005) Sensory evaluation and consumer acceptance of osmosed and oven-dried African star apple and African mango. Journal of Food, Agriculture and Environment 3: 91-96.

5. Rastogi NK, Niranjan K (1998) Enhanced mass transfer during osmotic dehydration of high pressure treated pineapple. J Food Sci 63: 508-511.

6. Rastogi NK, Angersbach A, Niranjan K, Knorr D (2000) Rehydration kinetics of high pressure pretreated and osmotically dehydrated pineapple. J Food Sci 65: 838-841.

7. Taiwo KA, Adeyemi $O$ (2009) Influence of blanching on the drying and rehydration of banana slices. African Journal of Food Science 3: 307-315.

8. Sandeep DB (2004) Effect of ohmic heating on color, rehydration and textural characteristics of fresh carrot cubes. Louisiana State University, India.

9. Ade-Omowaye BIO, Rastogi NK, Angersbach A, Knorr D (2002) Osmotic dehydration of bell peppers: influence of high intensity electric field pulses and elevated temperature treatment. J Food Eng 54: 35-43.

10. Taiwo KA, Eshtiaghi NM, Ade-Omowaye BIO, Knorr D (2003) Osmotic dehydration of strawberry halves: Influence of osmotic agents and pretreatment methods on mass transfer and product characteristics. Int J Food Sci Tech 38: 693-707.

11. Oyeyinka SA, Ade-Omowaye BIO, Ngoddy PO, Karim OR (2011) Selected Quality Attributes of Jam Produced from Osmo-Dehydrated Cashew Apple. J Food Technol 9: 27-31.

12. Taiwo KA, Angersbach A, Ade-Omowaye BIO, Knorr D (2001) Effects of Pretreatments on the Diffusion Kinetics and Some Quality Parameters of Osmotically Dehydrated Apple Slices. J Agric Food Chem 49: 2804-2811.

13. Taiwo KA, Angersbach A, Knorr D (2002) Influence of high intensity electric field pulses and osmotic dehydration on the rehydration characteristics of apple slices at different temperatures. J Food Eng 52: 185-192. 
Citation: Fasogbon BM, Gbadamosi SO, Taiwo KA (2013) Studies on the Osmotic Dehydration and Rehydration Characteristics of Pineapple Slices. J Food Process Technol 4: 220. doi:10.4172/2157-7110.1000220

14. Lerici CR, Pinnavaia G, Rosa DM, Bartolucci L (1985) Osmotic Dehydration of Fruit: Influence of Osmotic Agents on Drying Behaviour and Product Quality. J Food Sci 50: 1217-1219.

15. Hatem SA, Hesham AM, Mostafa TR, Gamal HR (2010) Osmotic Dehydration of Banana Rings and Tomato Halves. Journal of American Science 6: 383-390.

16. Suresh KP, Devi $P$ (2011) Optimization of some process variables in mass transfer kinetics of osmotic dehydration of pineapple slices. International Food Research Journal 18: 221-238.

17. Sapata ML, Ferreira A, Andrada L, Leitão AE, Candeias M (2009) Osmotic dehydration of mandarins: influence of reutilized osmotic agent on behaviour and product quality. Acta Scientiarum Polonorum Technologia Alimentaria 8: 23-35.
18. Singh B, Panesar SP, Nanda V (2007) Rehydration Kinetics of Un-Osmosed and Pre-Osmosed Carrot Cubes. World Journal of Dairy \& Food Sciences 2: 10-17.

19. Taiwo KA, Angersbach A, Knorr D (2002) Rehydration Studies on Pretreated and Osmotically Dehydrated Apple Slices. J Food Sci 67: 842-847.

20. Oliveira ARF, Ilincanu L (1999) In ARF Oliveira, JC Oliveira. Processing foods, quality optimization and process assessment. London CRC Press, pp 201-225.

21. Femenia A, Bestard MJ, Sanjuan N, Rossello C, Mulet A (2000) Effect of rehydration temperature on the cell wall components of broccoli (Brassica oleracea L. Var Italica) plant tissues. J Food Eng 46: 157-163.

22. Tregunno NB, Goff HD (1996) Osmodehydrofreezing of apples: structural and textural effects. Food Res Int 29: 471-479. 